\title{
Phenoxyacid Herbicides in Stormwater Retention Ponds: Urban Inputs
}

\author{
Renata Raina*, Michele L. Etter, Katherine Buehler, Kevin Starks, Ywomo Yowin \\ Department of Chemistry \& Biochemistry, Trace Analysis Facility, University of Regina, Regina, Canada \\ E-mail: renata.raina@uregina.ca \\ Received October 2, 2011; revised November 4, 2011; accepted November 14, 2011
}

\begin{abstract}
Surface water runoff from urban centers is a major source of environmental pollution which impacts water quality in downstream aquatic habitats. Phenoxyacid herbicides are some of the most widely globally used herbicides in agriculture and urban environments for weed control. Their transformation products which include chlorophenols can be more toxic than the active ingredients. We used LC/MS/MS to analyzed simultaneously these acid herbicides and their transformation products in stormwater retention ponds taken from an urban environment to examine the occurrence and potential release of these herbicides from urban inputs into downstream waters. 2,4-dichlorophenoxyacetic acid and mecoprop were detected in all samples collected from the ponds and at the highest concentrations, while 2-methyl-4-chlorophenoxyacetic acid was detected only in spring and summer. Two transformation products, 4-chloro-2-methylphenol and 2,4-dichlorophenol were detected in samples primarily at inlet locations on the ponds indicating that degradation had occurred in surface soils prior to surface water runoff.
\end{abstract}

Keywords: Phenoxyacid Herbicides, Chlorophenols, Stormwater Retention Ponds, LC/MS/MS

\section{Introduction}

Phenoxyacid herbicides were introduced in the 1940s and have widespread use in agriculture and urban areas to control the growth of broad-leaved weeds in cereal grains, oil seed, and legume crops and grasses. To improve their efficacy agricultural formulations often contain more than one acid herbicide such as 2,4-D (2,4dichlorophenoxyacetic acid) with dichlorprop or bromoxynil (a nitrile herbicide); and MCPA (4-chloro-2methylphenoxyacetic acid) with bromoxynil, MCPB (4-chloro-2-methylbenzoic acid), or dicamba [1]. Commercial formulations are also available for bromoxynil, MCPA and 2,4-D as an ester (2-ethylhexylesters) or alkaline salts (potassium or dimethylamine) rather than the free acid. However, the ester or salts of these herbicides undergoes hydrolysis in the environment to form the free acid [2]. The highest agricultural usage is expected in spring to early summer for crops such as wheat, barley, and flax $[3,4]$.

Phenoxyacid herbicides have been less widely studied than other herbicides but have been detected at $\mathrm{ng} \cdot \mathrm{L}^{-1}$ concentrations in surface waters throughout the prairies including wetlands, small prairie communities, and farm dugouts with 2,4-D $>$ MCPA $>$ dicamba $\sim$ bromoxynil $>$ dichlorprop $>$ MCPB [2-6]. Numerous other surface waters worldwide impacted by agricultural lands have reporting 2,4-D, mecoprop, or dichlorprop [7-14]. Pesticides can move in the environment by atmospheric transport, wet deposition, or be transported by surface rain-generated runoff from soils or surfaces [2,5,14-18]. As phenoxyacid herbicides have high water solubility ranging from $44 \mathrm{mg} \cdot \mathrm{L}^{-1}$ to $4500 \mathrm{mg} \cdot \mathrm{L}^{-1}$ (Table 1) surface water runoff is the major transport pathway. They are non-persistent in soil with $t_{1 / 2}<20$ days (except MCPA which is moderately persistent) [15,19], and have low volatility relative to other herbicides [6]. Factors important to surface water runoff include high precipitation events, mode of application, soil moisture, soil texture and topography, type and amount of ground cover, and distance of transport. Lower pesticide concentrations have been observed when there is less erosion, dry coarse textured soils, ground cover, shallow slopes for transport on surfaces, and soil-incorporated pesticides $[3,5,14,15]$.

Urban herbicide usage includes weed control for lawn and gardens, roadsides, golf courses, and parks and although not well documented nonagricultural usage may 
Table 1. Physical properties of the phenoxyacid herbicides.

\begin{tabular}{ccc}
\hline Compound & $\begin{array}{c}\text { Soil half-life } \\
(\text { days }) \dagger\end{array}$ & $\begin{array}{c}\text { Water solubility } \\
\left(\mathrm{mg} \cdot \mathrm{L}^{-1}\right) \dagger\end{array}$ \\
\hline MCPA & 5 & 825 \\
Mecoprop & 21 & 620 \\
MCPB & 14 & 44 \\
2,4-D acid & 10 & 900 \\
2,4-D iso-octyl ester & & $0.03 \dagger$ \\
2,4-D dimethylamine salt & 10 & $796000 \ddagger$ \\
Dichlorprop & 5 & 710 \\
2,4-DB & n.a. & 46 \\
2,4,5-TP & 7 & 200 \\
Bromoxynil & 4 & 130 \\
Dicamba & n.a. & 4500 \\
CMP & n.a. & 2300 \\
DCP & n.a. & 4600 \\
TCP & n.a. & 1200 \\
DBHBA & $2002 ; n . a$. \\
\hline
\end{tabular}

$\dagger$, MacKay et al., 2006; , Waite et al., 2002; n.a., indicates values are not available.

account for up to $25 \%$ of total pesticide usage in some regions of North America. The phenoxyacid herbicides $\mathrm{MCPB}$, dichlorprop, 2,4-DB and bromoxynil are not registered for use in urban areas and the use of 2,4,5-TP is not registered for both urban and agricultural use in Canada. Common domestic products generally include combinations of 2,4-D, MCPA, mecoprop and dicamba such as Killex $500^{\mathrm{TM}}$ which contains $385 \mathrm{~g} \cdot \mathrm{L}^{-1}$ 2,4-D, 75 $\mathrm{g} \cdot \mathrm{L}^{-1}$ mecoprop and $19 \mathrm{~g} \cdot \mathrm{L}^{-1}$ dicamba, CIL Golfgreen Weed \& Feed ${ }^{\mathrm{TM}}$ which contains 0.99 wt $\%$ 2,4-D and $0.495 \mathrm{wt} \%$ mecoprop, and Ortho ${ }^{\circledR}$ Weed B'Gon ${ }^{\circledR}$ Max which contains $0.22 \mathrm{wt} \%$ mecoprop, $0.12 \mathrm{wt} \% 2$,4-D and $0.05 \mathrm{wt} \%$. dicamba [20-23]. The common phenolxyacid herbicides such as 2,4-D have been detected in urban streams as well as surface and ground waters around golf courses throughout North America [24,25].

Phenoxyacid herbicides such as 2,4-D and MCPA are within the top 5 pesticides used for agriculture in the province of Saskatchewan (Canada) with 2003 provincial usage at $90,300 \mathrm{~kg}$, and $88,700 \mathrm{~kg}$, respectively. In 2003 dichlorprop, dicamba, mecoprop, and MCPB were used in much smaller quantities in agriculture at 26,700, 9800, 5800 , and $140 \mathrm{~kg}$, respectively [26]. Bromoxynil is often used in combination with the phenoxyacid acid herbicides and its 2003 usage was $27,500 \mathrm{~kg}$, similar to dichlorprop. No agricultural usage data is available for
Canada for 2007. The population of Regina continues to grow and is currently approximately 199,000. Retail sales are not available for homeowner usage, however 2007 usage in parkland and roadside areas by the City of Regina for 2,4-D, mecoprop and dicamba were 235, 46, and $11 \mathrm{~kg}$, respectively with no reported usage of MCPA or dichlorprop [27]. The objective of this study was to examine the occurrence of phenoxyacid herbicides in two stormwater retention ponds in an urban environment (the City of Regina) as phenoxyacid herbicides are registered for use in urban areas. For selected periods we also examined concentrations of phenoxyacid herbicides on Wascana Creek aquatic environment which receives inputs from the urban storm sewer system.

\section{Materials and Methods}

\subsection{Study Site Description and Sampling}

A total of 76 surface water samples were collected from two stormwater retention ponds from May to October, 2007 during the expected period of usage for herbicides. The stormwater retention ponds are located in the Windsor Park residential area of the City of Regina and are less than $1 \mathrm{~km}$ apart (Figure 1). The effluent from the stormwater ponds enters the City of Regina's underground storm sewer system which drains into Wascana Creek at the Prince of Wales storm trunk outlet just upstream of Rainbow Bridge. This storm trunk also collects water from storm drains in the east residential portion of the city. Several smaller creeks which receive stormwater runoff also directly release water into Wascana Creek. Two sampling locations were selected on Wascana Creek, a site upstream of urban inputs from the City of Regina in the Mckell Wascana Conservation Park (labeled Wascana View Bridge) which can be impacted by agricultural inputs, and a downstream site at Rainbow Bridge. This downstream site is also just upstream of the Wascana Country Club golf course (Figure 1). The two stormwater ponds are Windsor Park South and North. Windsor Park South water samples were collected at the north inlet structure and outlet of the pond, while Windsor Park North water samples were collected at the East dock nearby to the east inlet and at the west dock nearby to the outlet of the pond. Windsor Park South is a more established pond (1987) with surface area of $21,000 \mathrm{~m}^{2}$ and operating depth of $1.8 \mathrm{~m}$, while Windsor Park North was built in 2005 designed as a modified natural wetland. The surface area is $9000 \mathrm{~m}^{2}$ and its operating depth varies from 0.5 to $2.7 \mathrm{~m}$ with deeper areas near the inlet and outlet locations. At the time of the study the Windsor Park North pond was surrounded by new home construction and the landscape was not fully established. Water sam- 

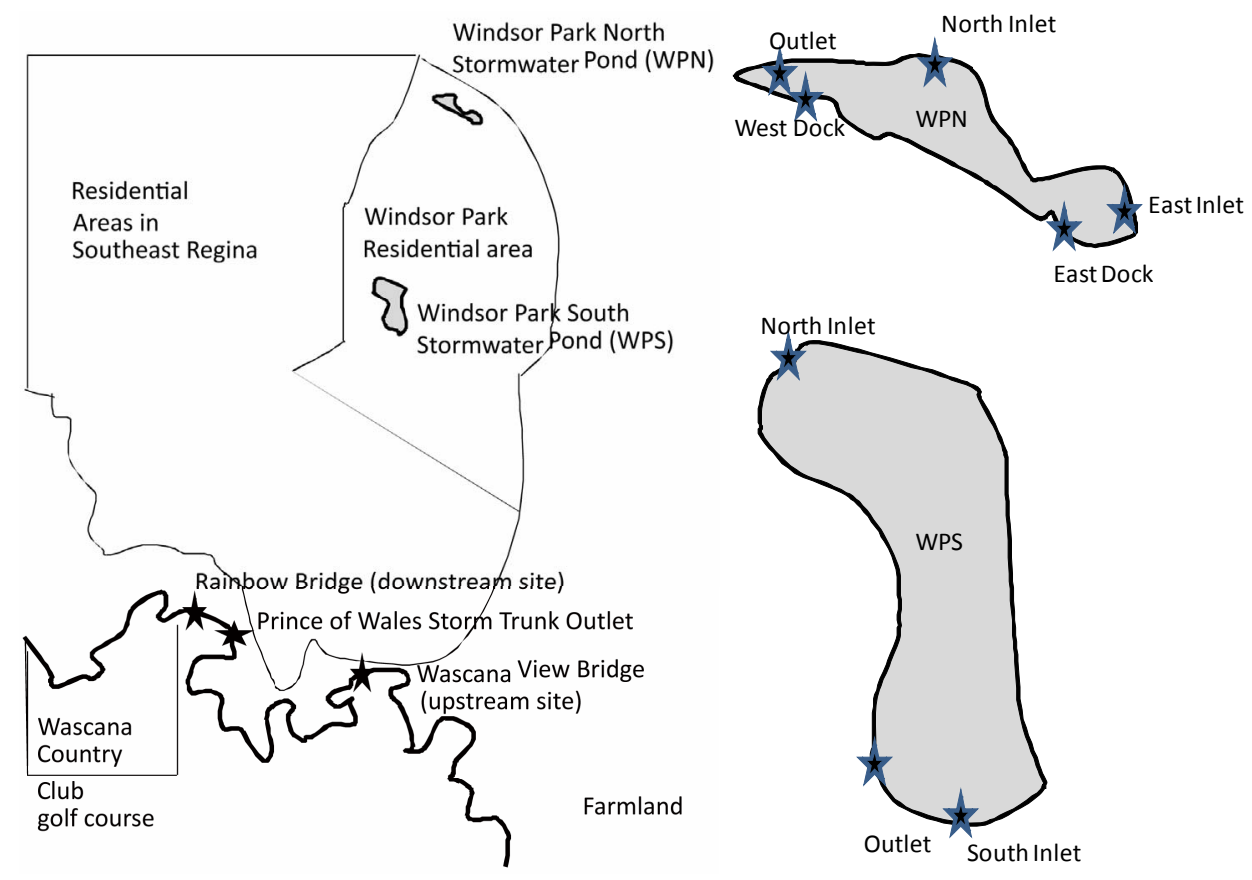

Figure 1. Map of Southeast Regina showing Windsor Park North (WPN), Windsor Park South (WPS), and Wascana Creek Upstream and Downstream Sampling Locations. Shown on right are expanded views of WPN and WPS stormwater ponds.

ples (1 L) were collected $10 \mathrm{~cm}$ below the surface of the ponds and a number of samples were also collected from a boat at different water depths (surface, approximately half-depth, and full depth) which did not show significant variation in concentrations. Precipitation data were obtained from Environment Canada for the City of Regina.

\subsection{Chemicals and Reagents}

The Individual herbicide or transformation product standards were prepared at $1.0 \mathrm{mg} \cdot \mathrm{mL}^{-1}$ from solids supplied by Chem Service Inc. (West Chester, PA, USA) and included (3,6-dichloro-2-methoxy)benzoic acid (dicamba), 3,5-dibromo-4-hydroxybenzonitrile (bromoxynil), 2methyl-4-chlorophenoxyacetic acid (MCPA), 2,4-dichlorophenoxyacetic acid (2,4-D), 2-(2-methyl-4-chlorophenoxy)propanoic acid (mecoprop), 2-(2,4-dichlorophenoxy)propanoic acid (dichlorprop), 4-(2,4-dichlorophenoxy)butanoic acid (2,4-DB), 2-(2-methyl-4-chlorophenoxy)butanoic acid (MCPB), 2,4,5-tichlorophenoxy propanoic acid (2,4,5-TP), 3,5-dibromo-4-hydroxybenzoic acid (DBHBA), 4-chloro-2-methylphenol (CMP), 2,4dichlorophenol (DCP), 2,4,5-trichlorophenol (TCP). Deuterated internal standard (2,4-dichlorophenoxy-3,56- $\mathrm{d}_{3}$-acetic- $\mathrm{d}_{2}$-acid $\left(\mathrm{d}_{5}-2,4-\mathrm{D}\right)$ was purchased as a solid from $\mathrm{C} / \mathrm{D} / \mathrm{N}$ Isotopes Inc. (Pointe-Claire, Quebec, QC, Canada) and ${ }^{13} \mathrm{C}_{6}$-2,4,5-trichlorophenoxyacetic acid $\left({ }^{13} \mathrm{C}_{6}-2,4,5-\mathrm{T}\right)$ and ${ }^{13} \mathrm{C}_{6}-2,4$-D were purchased from Cambridge Isotopes Laboratories (CIL) Inc., at 100 $\mu \mathrm{g} \cdot \mathrm{mL}^{-1}$. These solutions were further diluted to 1000 $\mathrm{ng} \cdot \mathrm{mL}^{-1}$ with pesticide grade methanol (Fisher Scientific, Ottawa, ON, Canada) for standard solution preparation. It should be noted that 2,4,5-trichlorophenoxy-3, $6-\mathrm{d}_{2}-$ acetic- $\mathrm{d}_{2}$-acid $\left(\mathrm{d}_{4}-2,4,5-\mathrm{T}\right)$ is now available from $\mathrm{C} / \mathrm{D} / \mathrm{N}$ isotopes and can be used to replace ${ }^{13} \mathrm{C}_{6}-2,4,5$-T. Stock solutions were diluted to $1000 \mathrm{ng} \cdot \mathrm{mL}^{-1}$ with pesticide grade methanol for use.

Materials used for sample preparation included ethyl acetate and methanol (pesticide grade, Fisher Scientific). Deionized water was $(<18 \mathrm{M} \Omega \mathrm{cm}$ resistivity) obtained from a Nanopure diamond ${ }^{\mathrm{TM}}$ system (Barnstead International, Dubuque, Iowa, USA). OmniPur ammonium acetate $(>97 \%)$ and OmniTrace Ultra ammonia hydroxide $(>99 \%)$ were obtained from EMD Biosciences (Gibbstown, NJ, USA) and used in mobile phase and postcolumn reagent preparation required for LC/MS/MS analysis. All mobile phase solvents were passed through $0.45 \mu \mathrm{m}$ membrane filters from Nucleopore (Whatman, Florham Park, NJ, USA). HPLC grade glacial acetic acid was obtained from EMD Biosciences (Gibbstown, NJ, USA) and used for $\mathrm{pH}$ adjustment of water samples.

\subsection{Sample Preparation and LC/MS/MS}

A detailed description of the sample filtration, solid phase extraction (SPE), and liquid chromatography-tandem mass spectrometry (LC/MS/MS) analysis used for quantifying the acid herbicides and their transformation 
products can be found in Raina and Etter [28]. Filters used for water sample filtration included Whatman 934-AD, Whatman 41 ashless and Whatman $0.45 \mu \mathrm{m}$ nylon membrane filters (Canadawide Scientific, Ottawa, $\mathrm{ON}$, Canada). A sequential filtration approach to smaller pore size filters was used to reduce plugging of filters and to speed up the filtration process. Following filtration samples were acidified to $\mathrm{pH} 4.9$ and $10 \mathrm{~mL}$ of pesticide grade methanol was added to facilitate flow for SPE. ENVI-Chrom P, 1 g, 6 mL SPE tubes (Sigma-Aldrich, Oakville, ON, Canada) were used to concentrate the pesticides. Water samples were drawn through the SPE cartridge at a rate of $200 \mathrm{~mL} \cdot \mathrm{hr}^{-1}$ by vacuum manifold and then the SPE cartridges were dried with nitrogen for 5 minutes until constant weight was achieved. The filtration and SPE procedures were completed within 24 hours of sample collection and dried SPE cartridges were stored at $-4^{\circ} \mathrm{C}$ until analysis. Herbicides were eluted with $8 \mathrm{~mL}$ of $60 / 40 \mathrm{v} / \mathrm{v} \%$ methanol/ethylacetate and dried to $\sim 0.95 \mathrm{~mL}$ followed by addition of a dilution standard ${ }^{13} \mathrm{C}_{6}-2,4,5-\mathrm{T}\left(50 \mu \mathrm{L}\right.$ of $\left.1.0 \mu \mathrm{g} \cdot \mathrm{mL}^{-1}\right)$. SPE recoveries evaluated with ${ }^{13} \mathrm{C}_{6}-2,4-\mathrm{D}$ were $90 \% \pm 10 \%$. An internal standard $\mathrm{d}_{5}-2,4-\mathrm{D}\left(50 \mu \mathrm{L}\right.$ of $\left.1.0 \mu \mathrm{g} \cdot \mathrm{mL}^{-1}\right)$ was used for the LC/MS/MS analysis [28]. LC/MS/MS analyses were performed at the Trace Analysis Facility at the University of Regina using a Waters LC system consisting of a $1525 \mu$ binary pump, column heater, and a Quattro Premier tandem mass spectrometer (Waters-Micromass, Milford, MA, USA) with electrospray ionization operated in negative ion mode. Post column reagent addition of ammonium in methanol into a mixing tee using a Shimadzu model LC-20AD pump (Man-Tech Associates,
Guelph, ON, Canada) was used to improve the sensitiveity of the transformation products. Herbicide concentrations reported herein represent the dissolved fraction. The method detection limits (MDLs) are $2 \mathrm{ng} \cdot \mathrm{L}^{-1}$ for TCP; $5 \mathrm{ng} \cdot \mathrm{L}^{-1}$ for bromoxynil, MCPA, dichlorprop, and 2,4-DB; $10 \mathrm{ng} \cdot \mathrm{L}^{-1}$ for 2,4-D, mecoprop, MCPB, 2,4,5-TP, and DCP; $20 \mathrm{ng} \cdot \mathrm{L}^{-1}$ for $\mathrm{CMP}$; and $30 \mathrm{ng} \cdot \mathrm{L}^{-1}$ for dicamba and DBHBA. The MDL represents the minimum concentration showing $<25 \%$ deviation of peak area from the best-fit regression lines of the calibration curves for both the quantitative and confirmation selected reaction monitoring transitions [28]. Calibration standards ranged from MDL to $150 \mathrm{ng} \cdot \mathrm{L}^{-1}$ with internal standard $\left(\mathrm{d}_{5}-2,4-\mathrm{D}\right)$ at $100 \mathrm{ng} \cdot \mathrm{L}^{-1}$. Higher concentration samples were diluted into the calibration range.

\section{Results}

\subsection{Occurrence of Herbicides in Urban Stormwater Retention Ponds}

A total of 9 herbicides and 4 transformation products were analyzed in water samples collected from the two stormwater ponds. Herbicides MCPB, 2,4-DB, 2,4,5-TP, dicamba and bromoxynil as well as the two transformation product of 2,4,5-TP and bromoxynil (TCP and DBHBA) were not detected in any of the samples. MCPB, 2,4-DB, 2,4,5-TP, and bromoxynil are not Registered for use in urban areas. However, dichlorprop which is also not registered for use in urban areas was detected in both Windsor Park South and North ponds (Table 2). The City of Regina is surrounded by one of Canada's

Table 2. Concentrations of Phenoxyacid Herbicides and Transformation Products Detected at Inlet and Outlet Locations for two stormwater retention ponds.

\begin{tabular}{|c|c|c|c|c|c|}
\hline Analyte & Inlet Range (Average) $\mathrm{ng} \cdot \mathrm{L}^{-1}$ & Inlet Df (\%) & Outlet Range (Average) ng $\cdot \mathrm{L}^{-1}$ & Outlet Df (\%) & p-value \\
\hline \multicolumn{6}{|c|}{ Windsor Park South } \\
\hline $2,4-\mathrm{D}$ & $111-1341(593)$ & 100 & $137-1538(570)$ & 100 & 0.81 \\
\hline Mecoprop & $281-1094(666)$ & 100 & $361-1625(750)$ & 100 & 0.27 \\
\hline MCPA & $21-186(52)$ & 60 & $19-180(53)$ & 85 & 0.94 \\
\hline Dichlorprop & $47-1260(816)$ & 7 & $54-58(56)$ & 10 & 0.22 \\
\hline CMP & $27-33(31)$ & 13 & n.d. & 15 & 0.29 \\
\hline DCP & $\begin{array}{c}22-50 \\
(38)\end{array}$ & 20 & n.d. & 0 & - \\
\hline \multicolumn{6}{|c|}{ Windsor Park North } \\
\hline 2,4-D & $105-2755(795)$ & 100 & $136-1961(562)$ & 100 & 0.30 \\
\hline Mecoprop & $351-2403(917)$ & 100 & $326-1528(815)$ & 100 & 0.55 \\
\hline MCPA & $12-379(178)$ & 70 & $11-189(81)$ & 73 & 0.05 \\
\hline Dichlorprop & $77-116(102)$ & 11 & $59-96(73)$ & 20 & 0.17 \\
\hline CMP & $33-101(53)$ & 19 & n.d. & 0 & - \\
\hline DCP & $302(302)$ & 4 & n.d. & 0 & - \\
\hline
\end{tabular}


highest production regions for cereal grains and oil seeds worldwide and suggests that there may be some unregistered use of agricultural formulations within city limits. Dichlorprop is used in agricultural formulations such as Estaprop or Turboprop, both which contain $300 \mathrm{~g} \cdot \mathrm{L}^{-1}$ of dichlorprop and $282 \mathrm{~g} \cdot \mathrm{L}^{-1}$ of 2,4-D [22]. In addition Table 2 shows that the concentration range of dichlorprop at Windsor Park South was much greater than at Windsor Park North which is a new residential area. Figure 2(a) shows higher levels of 2,4-D for August 21 which also

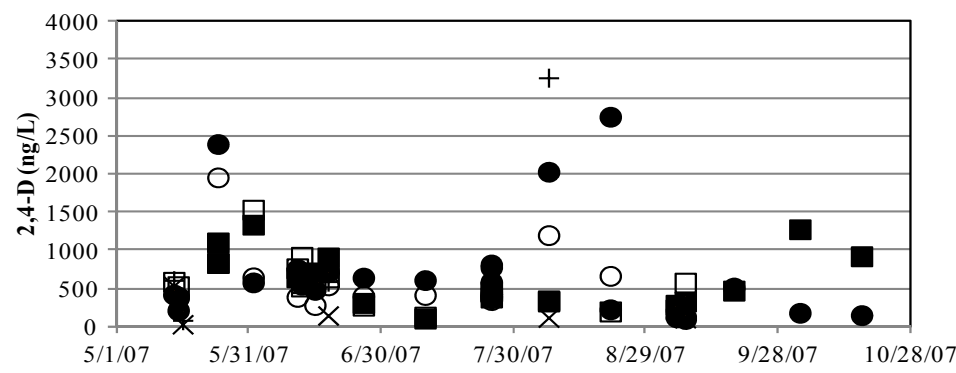

(a)

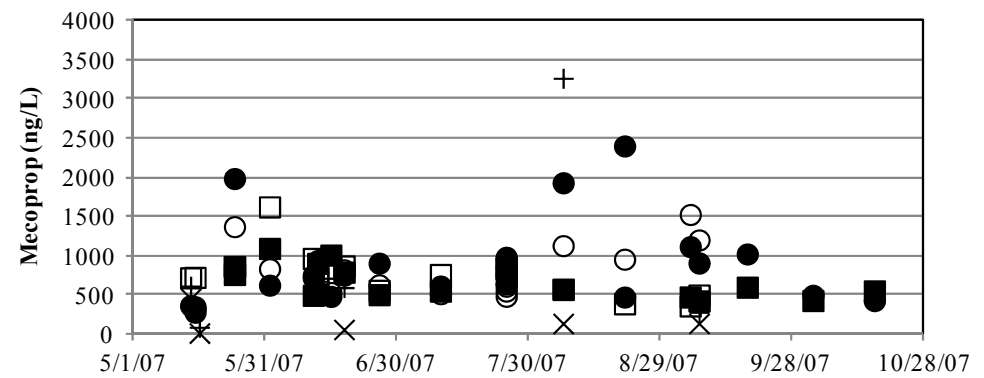

(b)

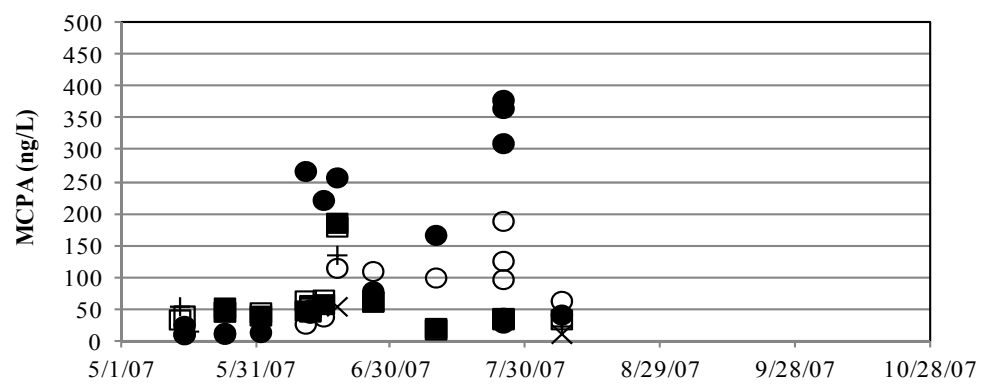

(c)

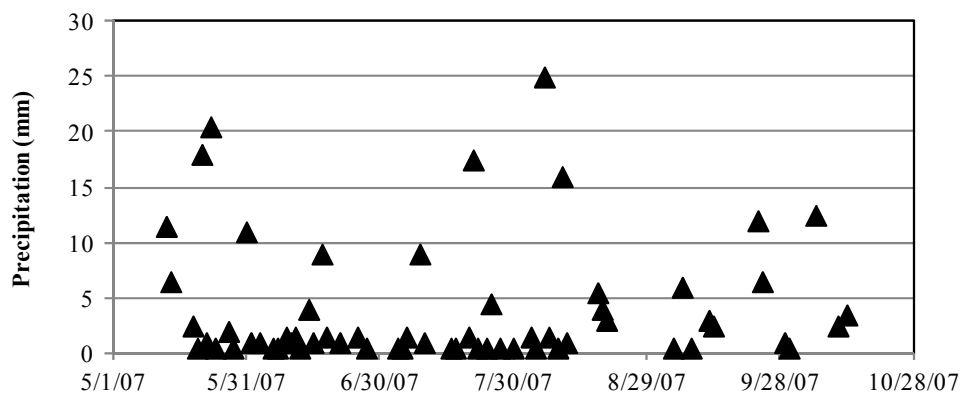

(d)

Figure 2. Phenoxyacid Herbicide Concentrations in Two Stormwater Retention Ponds and Precipitation Amounts in the City of Regina. (a), 2,4-D; (b), mecoprop; (c), MCPA; (d), daily precipitation amount. WPN: Windsor Park North stormwater pond; and WPS, Windsor Park South stormwater pond. Note: MCPA was not detected in samples collected during Sept-Oct, 2007. - WPS Inlet; • WPN Inlet; $\square$ WPS Outlet; $\odot$ WPS Outlet; $\times$ Wascana Creek Upstream; + Wascana Creek Downstream; and $\boldsymbol{\Delta}$ total daily precipitation (obtained from Environment Canada). 
had the highest concentrations of dichlorprop at the inlet of Wascanca Park South. Both dichlorprop and 2,4-D are present in the Turboprop formulation. Dichlorprop has a short half-life (Table 1) [19] and its presence is expected to be due to recent residential usage. Dichlorprop was not detected at the upstream Wascana Creek site which receives water inputs from agricultural land indicating that the concentrations detected in the ponds is from recent urban inputs.

Table 2 shows that 2,4-D and mecoprop were detected in all samples taken from the two ponds and observed the highest concentrations of the herbicides analyzed with concentrations of 2,4-D and mecoprop reaching 2755 $\mathrm{ng} \cdot \mathrm{L}^{-1}$ and $2403 \mathrm{ng} \cdot \mathrm{L}^{-1}$, respectively at Windsor Park North inlet and $1204 \mathrm{ng} \cdot \mathrm{L}^{-1}$ and $1528 \mathrm{ng} \cdot \mathrm{L}^{-1}$, respectively at Windsor Park South inlet. MCPA had a lower detection frequency and was observed at lower concentrations in the two ponds than 2,4-D or mecoprop. CMP, a transformation product of mecoprop and MCPA as well MCPB (not detected) was detected in only 5 samples collected from Windsor Park North and 5 samples collected from Windsor Park South. The detections in Windsor Park North (June 12, 18, August 7, 21 and September 5) were all from the inlet location. The detections in Windsor Park South were at both the inlet location (June 11 and 26) and the outlet location (June 12, 18 and July 25). DCP, a transformation product of 2,4-D and dichlorprop as well as 2,4-DB (not detected) was found in only 1 sample on August 21 at the inlet location in Windsor Park North, and 3 samples at the inlet location in Windsor Park South (June 15, October 3 and 17). Given that these detections of CMP and DCP occur primarily in water samples taken at the inlet locations, this suggests that degradation of the phenoxyacid herbicides has occurred in soils from residential areas surrounding the stormwater ponds prior to surface water runoff after a rainfall event. Previous studies on contaminated agricultural soils have shown that photodecomposition dominates over microbial action in surface soils with $\mathrm{t}_{1 / 2} \sim 5$ days and peak concentrations after 8 days with no irrigation [29] thus indicating recent usage. Rainfall had occurred on the day or previous day to sampling for all periods where DCP or CMP were detected at the inlet. In aquatic systems the aerobic biogradation of phenoxyacids is expected to be fast (within 14 days) [30], however DCP and CMP had a lower frequency of detection at outlet locations and indicates that the residence time of water in the ponds was too short or microbial communities were not sufficient to provide significant biodegradation of the herbicides. Figure 2(d) shows that there was frequent rainfall during our study period $(39 \%$ of days), and 13 periods with rainfall for several days in a weekly period and the majority of these periods with one day or more with precipitation greater than $5 \mathrm{~mm}$. The stormwater ponds release water based upon the water level in the ponds and generally these rainfall events were sufficient to see movement of water to the storm sewer system. Water flows at inlet and outlet locations were not available.

\subsection{Seasonal Variations in Herbicide Concentrations}

Phenoxyacid herbicides are used for lawn care for weed control including during periods of fertilizing. 2,4-D shows a maximum in concentrations in May, and a second maximum in concentrations during late summerearly fall (Figure 2(a)). Although 2,4-D inlet concentration range is smaller at Windsor Park South than Windsor Park North (Table 2), the spring maximum is more evident and the second maximum in 2,4-D concentrations occurs latter in the season (September) at Windsor Park South than at Windsor Park North (August). This may be partially related to the fact that Windsor Park South is a more establish pond and residential area, whereas at the time of this study there was still new home construction around Windsor Park North pond with incomplete landscaping (ground cover) and high flow of surface runoff and flooding apparent during some rainfall events. Mecoprop observes similar seasonal maximum at both ponds (Figure 2(b)) and is often used in combination with 2,4-D. The higher concentrations of 2,4-D and mecoprop are expected to be dependent upon both fresh usage and rainfall. The rainfall event at the start of the study on May 13-14 did not observed high phenoxyacid concentrations, however samples collected after the period of rainfall on May 19-23 showed much higher concentrations. Greater dilution effect for periods on or just after days with heavier rainfall (May 24, August 7 and 21) could be observed between inlet and outlet concentrations particularly for Windsor Park North stormwater pond.

MCPA, which has a lower detection frequency than 2,4-D and mecoprop, observes detectable concentrations only during spring and summer. At the more established pond (Windsor Park South) the highest concentration was observed in mid-June, while at Windsor Park North high concentrations were observed during this period as well as on July 25 when rainfall occurred (Figure 2(c)). These shifts in seasonal trends are related to the different phenoxyacid formulations in use during the summer months.

A number of formulations including Killex 500, CIL Weed n'Feed, and Weed B'Gon contain both 2,4-D and mecoprop which were the two most abundant phenoxyacid herbicides detected. Figure 3(a) shows the ratio of 2,4-D/mecoprop determined for water samples collected 


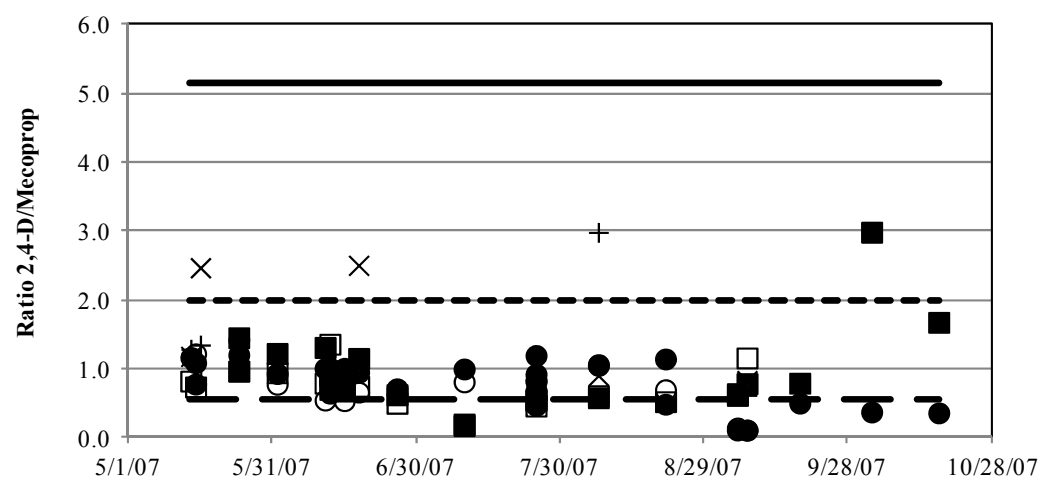

(a)

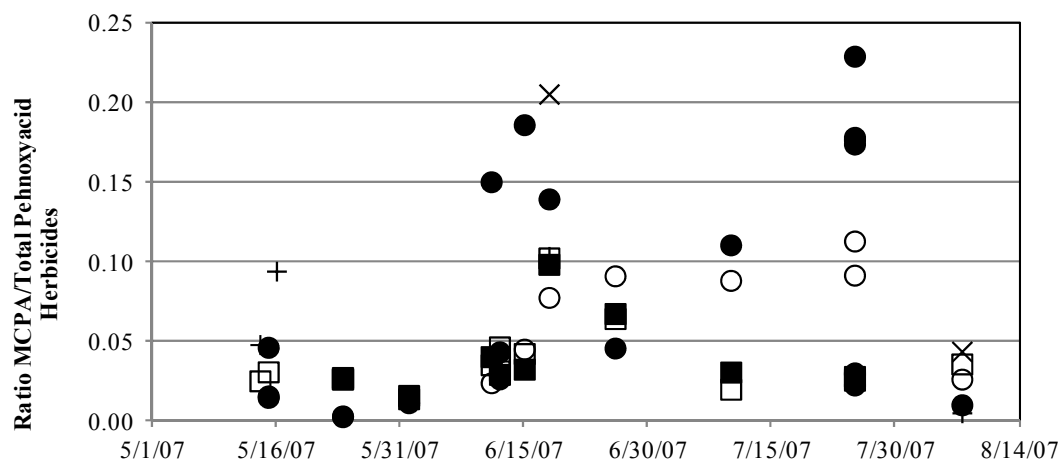

(b)

Figure 3. Ratio of 2,4-D/Mecoprop and MCPA/Total Phenoxyacid Herbicides in Water Samples collected from two stormwater retention ponds. (a), 2,4-D/Mecoprop; and (b), MCPA/Total Phenoxyacid Herbicides. WPN: Windsor Park North stormwater pond; and WPS, Windsor Park South stormwater pond. Note: MCPA was not detected in September and October, 2007. - WPS Inlet; • WPN Inlet; $\square$ WPS Outlet; $\bigcirc$ WPS Outlet; $\times$ Wascana Creek Upstream; + Wascana Creek Downstream; and Ratio 2,4-D/Mecoprop (shown as line in A): Killex, 5.15; CIL Weed n'Feed, 2.0; and Weed B'Gon, 0.55.

from the ponds. The ratio is generally between the range expected for the Weed B'Gon and CIL Weed n'Feed formulations and lower than the Killex 500 formulation. Some periods of higher ratio of 2,4-D/mecoprop latter in the season (October 3 and 17) may also be influenced by Killex 500 usage such as by City of Regina in parkland areas or may be the result of 2,4-D from unregistered use of formulations containing dichlorprop (which also contains 2,4-D). In general Wascana Creek downstream concentrations also indicated similar ratios as the stormwater ponds with exception of the August 7th at the downstream Wascana Creek site (Rainbow Bridge) which had higher concentrations and may be due to applications of Killex 500 in parklands nearby to Wascana Creek. Upstream ratio of 2,4-D/mecoprop in spring can be higher than that of the stormwater ponds, however the downstream ratio was reduced to similar range to that of the stormwater ponds.

MCPA is present in formulations that contain bromoxynil and dicamba and not expected to be used in combination with 2,4-D or mecoprop. The Killex formulation used by the City of Regina does not contain
MCPA. There are formulations available for retail sales to homeowners such as Yates Liquid Weed'n'Feed ${ }^{\mathrm{TM}}$ which contains $15 \mathrm{~g} \cdot \mathrm{L}^{-1} \mathrm{MCPA}$ and $2.3 \mathrm{~g} \cdot \mathrm{L}^{-1}$ dicamba [31]. Figure 3(b) shows the ratio of MCPA/total phenoxyacid herbicides for those sampling periods with detectable concentrations of MCPA in spring and summer. These ratios like MCPA concentrations are higher during early to mid-summer with the higher ratio at Windsor Park North indicating a greater influence of usage of MCPA formulations in the new home construction residential area. In this new residential area we may be observing both homeowner and lawncare providers use of different formulations for landscape of new properties. The Windsor Park North site observed more direct surface runoff from lawns directly adjacent to the ponds as attributed to less established ground cover to retain water and the steeper topology of the surrounding area.

\subsection{Stormwater Ponds and Wascana Creek Herbicide Concentrations}

Although the range in phenoxyacid herbicide concentra- 
tions varied significant during March-October 2007, there was no significant difference in average concentrations between the two ponds except for MCPA which showed higher average concentrations at Windsor Park North $\left(132 \mathrm{ng} \cdot \mathrm{L}^{-1}\right)$ as compared to Windsor Park South $53 \mathrm{ng} \cdot \mathrm{L}^{-1}(\mathrm{p}=0.0008)$. For 7 sampling periods where rainfall had occurred the concentrations of phenoxyacid herbicides and their transformation products were also measured at the upstream and downstream locations on Wascana Creek. Dichlorprop was detected in some water samples collected at the outlet of the Windsor Park South but was not detected in Wascana Creek samples. The detection frequency of 2,4-D, mecoprop, MCPA, and the two transformation products (DCP and CMP) was higher at the downstream site than the upstream site on Wascana Creek. Average concentrations of 2,4-D, and mecoprop in Windsor Park South were significantly higher than the upstream Wascana Creek site, but only MCPA was significantly higher than the downstream location. This indicates that urban inputs from the storm sewer system influenced concentrations downstream and in general as previously discussed the ratio of 2,4-D/mecoprop at the downstream location was similar to the stormwater ponds. Windsor Park South pond is a significant source of inputs and is also in closer proximity to the release point of the storm sewer system into Wascana Creek than Windsor Park North and consequently would exhibit less dilution during water transport. Mecoprop average concentration was also higher at the Wascana Creek North pond than water samples taken from the upstream location on Wascana Creek for these sampling periods. During the study period of May-October, 2007 only 3 sampling periods in Windsor Park North and one of the seven sampling periods on Wascana Creek downstream exceeded the Canadian water quality guideline for the protection of aquatic life (4000 $\mathrm{ng} \cdot \mathrm{L}^{-1}$ for total phenoxyacid herbicides) [32].

\section{Conclusions}

The most frequently detected phenoxyacid herbicides in the two urban stormwater ponds were 2,4-D and mecoprop consistent with phenoxyacid formulations such as Weed b'Gon and CIL Weed n'Feed. Higher concentrations of these phenoxyacid herbicides were observed in spring and late summer-fall. Ratios of 2,4-D/mecoprop were similar for samples collected at a downstream site on Wascana Creek and indicate that urban usage influenced concentrations of phenoxyacids on Wascana Creek. However, most sampling periods had total phenoxyacid herbicides below the Canadian water quality guideline for the protection of aquatic life. MCPA was detected only in spring and summer and had a different seasonal variation than 2,4-D and mecoprop. There were higher average concentrations of MCPA for Windsor Park North where new home construction was still taking place during this study period. It indicates in these two residential areas that there are differences in formulations used for control of weeds on lawns. Dichlorprop, which is not registered for use in urban areas, was detected in both ponds and indicates that there may be unregistered usage of agricultural formulations in urban areas such as Regina which is surrounded by a high production agricultural region for grains and oil seeds. Detection of transformation products (CMP and DCP) were more commonly observed at inlet locations on the ponds. This indicates that their degradation had occurred prior to surface water runoff to the ponds. Rainfall events often occurred over several days with insufficient time or environment within the ponds to observe further degradation of the phenoxyacid herbicide. Higher detection frequency of CMP and DCP were also observed during warmer months (summer-fall) although concentrations and detection frequency were much lower than their parent phenoxyacid herbicides.

\section{Acknowledgements}

This work was financially supported by Natural Sciences and Engineering Research Council (NSERC) Discovery Grant, and instrumental and facility support for the Trace Analysis Facility from Canadian Foundation for Innovation (CFI). Staff from City of Regina and National Research Council-Centre for Sustainable Infrastructure Research assisted with sampling, and total precipitation data was obtained from Environment Canada.

\section{References}

[1] Saskatchewan Ministry of Agriculture, "Guide to Crop Protection Weeds, Plant Diseases, Insects,” 2010. http://www.agriculture.gov. sk.ca

[2] D. T. Waite, A. J. Cessna, R. Grover, L. A. Kerr and A. D. Snihura, "Environmental Concentrations of Agricultural Herbicides in Saskatchewan, Canada: Bromoxynil, Dicamba, Diclofop, MCPA, and Trifluralin," Journal of Environmental Quality, Vol. 33, No. 5, 2004, pp. 16161628. doi: $10.2134 /$ jeq2004.1616

[3] D. B. Donald, N. P. Gurpradasad, L. Quinnett-Abbott and K. Cash, "Diffuse Geographic Distribution of Herbicides in Northern Prairie Wetlands," Environmental Toxicology and Chemistry, Vol. 20, No. 2, 2001, pp. 273-279. doi:10.1002/etc.5620200207

[4] A. J. Cessna and J. A. Elliot, "Seasonal Variation of Herbicide Concentrations in Prairie Farm Dugouts," Journal of Environmental Quality, Vol. 33, No. 1, 2004, pp. 302315. doi:10.2134/jeq2004.0302

[5] D. B. Donald, F. G. Hunter, E. Sverko, B. D. Hill and J. 
Syrgiannis, "Mobilization of Pesticides on an Agricultural Landscape Flooded by a Ttorrential Storm," Environmental Toxicology and Chemistry, Vol. 24, No. 1, 2005, pp. 2-10. doi:10.1897/03-668.1

[6] D. T. Waite, A. J. Cessna, R. Grover, L. A. Kerr and A. D. Snihura, "Environmental Concentrations of Agricultural Herbicides: 2,4-D and Triallate," Journal of Environ- mental Quality, Vol. 31, No. 1, 2002, pp. 129-144. doi:10.2134/jeq2002.0129

[7] T. D. Bucheli, S. R. Müller, S. Heberle and R. P. Schwarzenbach, "Occurrence and Behavior of Pesticides in Rainwater, Roof Runoff, and Artificial Stormwater Infiltration," Environmental Science and Technology, Vol. 32, No. 22, 1998, pp. 3457-3464. doi:10.1021/es980317n

[8] S. Chiron, L. Comoretto, E. Rinaldi, V. Maurino, C. Minero and D. Vione, "Pesticide By-Products in the Rhône Delta (Southern France). The Case of 4-Chloro2-methylphenol and of Its Nitroderivative," Chemosphere, Vol. 74, No. 4, 2009, pp. 599-604. doi:10.1016/j.chemosphere.2008.09.012

[9] S. Chiron, C. Minero and D. Vione, "Occurrence of 2,4Dichlorophenol and of 2,4-Dichloro-6-nitrophenol in the Rhône River Delta (Southern France)," Environmental Science and Technology, Vol. 41, No. 9, 2007, pp. 31273133. doi:10.1021/es0626638

[10] G. Felding, "Leaching of Phenoxyalkanoic Acid Herbicides from Farmland," Science of the Total Environment, Vol. 168, No. 1, 1995, pp. 11-18. doi:10.1016/0048-9697(95)04477-I

[11] G. Felding, J. B. Sorenson, B. B. Mogensen and A. C. Hansen, "Phenoxyalkanoic Acid Herbicides in Run-Off," Science of the Total Environment, Vol. 175, No. 3, 1995, pp. 207-218. doi:10.1016/0048-9697(95)04847-2

[12] W. A. House, D. Leach, J. L. A. Long, P. Cranwell, C. Smith, L. Bharwaj, A. Meharg, G. Ryland, D. O. Orr and J. Wright, "Micro-Organic Compounds in the Humber Rivers," Science of the Total Environment, Vol. 194-195, 1997, pp. 357-371. doi:10.1016/S0048-9697(96)05375-2

[13] S. Marchese, D. Perret, A. Gentili, G. D'Ascenzo and A. Faberi, "Determination of Phenoxyacid Herbicides and Their Phenolic Metabolites in Surface and Drinking Water," Rapid Communications in Mass Spectrometry, Vol. 16, No. 2, 2002, pp. 134-141. doi:10.1002/rcm.557

[14] H. Blanchoud, F. Farrugia and J. Mouchel, "Pesticide Uuses and Transfers in Urbanized Catchments," Chemosphere, Vol. 55, No. 6, 2004, pp. 905-913. doi:10.1016/j.chemosphere.2003.11.061

[15] G. H. Willis and L. L. McDowell, "Pesticides in Agricultural Runoff and Their Effects on Downstream Water Quality," Environmental Toxicology and Chemistry, Vol. 1, 1982, pp. 267-279.

[16] J. R. De Lipthay, R. Sørensen and J. Aamand, "Effect of Herbicide Concentration and Organic and Inorganic Nutrient Amendment on the Mineralization of Mecoprop, 2,4-D and 2,4,5-T in Soil and Aquifer Samples," Environmental Pollution, Vol. 148, No. 1, 2007, pp. 83-93. doi:10.1016/j.envpol.2006.11.005

[17] A. M. Peck and K. C. Hornbuckle, "Gas-Phase Concen- trations of Current-Use Pesticides in Iowa," Environmental Science and Technology, Vol. 39, No. 9, 2005, pp. 2952-2959. doi:10.1021/es0486418

[18] I. K. Wittmer, H.-P. Bader, R. Scheidegger, H. Singer, A. Luck, I. Hanke, C. Carlsson and C. Stamm, "Significance of Urban and Agricultural Land Use for Biocide and Pesticide Dynamics in Surface Waters," Water Research, Vol. 44, No. 9, 2010, pp. 2850-2862. doi:10.1016/j.watres.2010.01.030

[19] D. Mackay, W. Shiu, K. Ma and S. C. Lee, "Handbook of Physical-Chemical Properties and Environmental Fate for Organic Chemicals," 2nd Edition, CRC Press, Boca Raton, 2006.

[20] Pesticide Management Regulatory Agency (PRMA), "Label Transcript Killex $500^{\circledR}$ Liquid Turf Herbicide Concentrate," Scotts Canada Ltd., Mississauga, 2010.

[21] Material Safety Data Sheet (MSDS), "Ortho® Weed B'Gon ${ }^{\circledR}$ Max $^{\mathrm{TM}}, 2004$.

[22] Material Safety Data Sheet (MSDS), “Green-Up 15-2-3, Weed \& Feed (CIL Golfgreen Weed \& Feed)," Sure-Gro Inc, 2006.

[23] Material Safety Data Sheet (MSDS), “Turboprop® PCP 27967," United Agri Products Canada, Inc, 2008.

[24] R. S. Hoffman, P. D. Capel and S. J. Larson, "Comparison of Pesticides in Eight U.S. Urban Streams," Environmental Toxicology and Chemistry, Vol. 19, No. 9, 2000, pp. 2249-2258. doi:10.1002/etc.5620190915

[25] R. D. Baris, S. Z. Cohen, N. L. Barnes, J. Lam and Q. Ma, "Quantitative Analysis of over 20 Years of Golf Course Monitoring Studies," Environmental Toxicology and Chemistry, Vol. 29, No. 6, 2010, pp. 1224-1236.

[26] Personnel Communication, Saskatchewan Agriculture, "Saskatchewan Usage Inventory 2003-2005," 2009.

[27] Personnel Communication, "Regina Usage Inventory 2007," City of Regina, 2009.

[28] R. Raina and M. L. Etter, "Liquid Chromatography and Tandem Mass Spectrometry for Herbicides in Water," Analytical Chemistry Insights, Vol. 5, 2010, pp. 1-14. doi:10.4137/ACI.S3148

[29] M. A. Crespln, M. Gallego and M. Valcárcel, " Study of the Degradation of the Herbicides 2,4-D ad MCPA at Different Depths in Contaminated Agricultural Soil," Environmental Science and Technology, Vol. 35, No. 21, 2001, pp. 4265-4270. doi:10.1021/es0107226

[30] J. Harrison, R. U. Leader, J. J. W. Higgo and G. M. Williams, "A Study of the Degradation of Phenoxyacid Herbicides at Different Sites in a Limestone Aquifer," Chemosphere, Vol. 36, No. 6, 1998, pp. 1211-1232. doi:10.1016/S0045-6535(97)10043-1

[31] Material Safety Data Sheet (MSDS), "Yates Liquid Weed n Feed Hose on Yates Australia, a Division of DuluxGroup (Australia) Pty Ltd," 2010.

[32] Canadian Council of Ministers of the Environment, "Canadian Environmental Quality Guidelines," Canadian Council of Ministers of the Environment, Winnipeg, 2007. 